\title{
As mudanças na lei de partilha do pré-sal e o bloqueio do desenvolvimento nacional
}

\section{changes in the pre-salt oil sharing law and blocking to national development}

\section{André Pereila R. Tokarski*}

DOI: https://doi.org/10.4322/principios.2675-6609.2020.160.014

Dilvugação/Petrobras

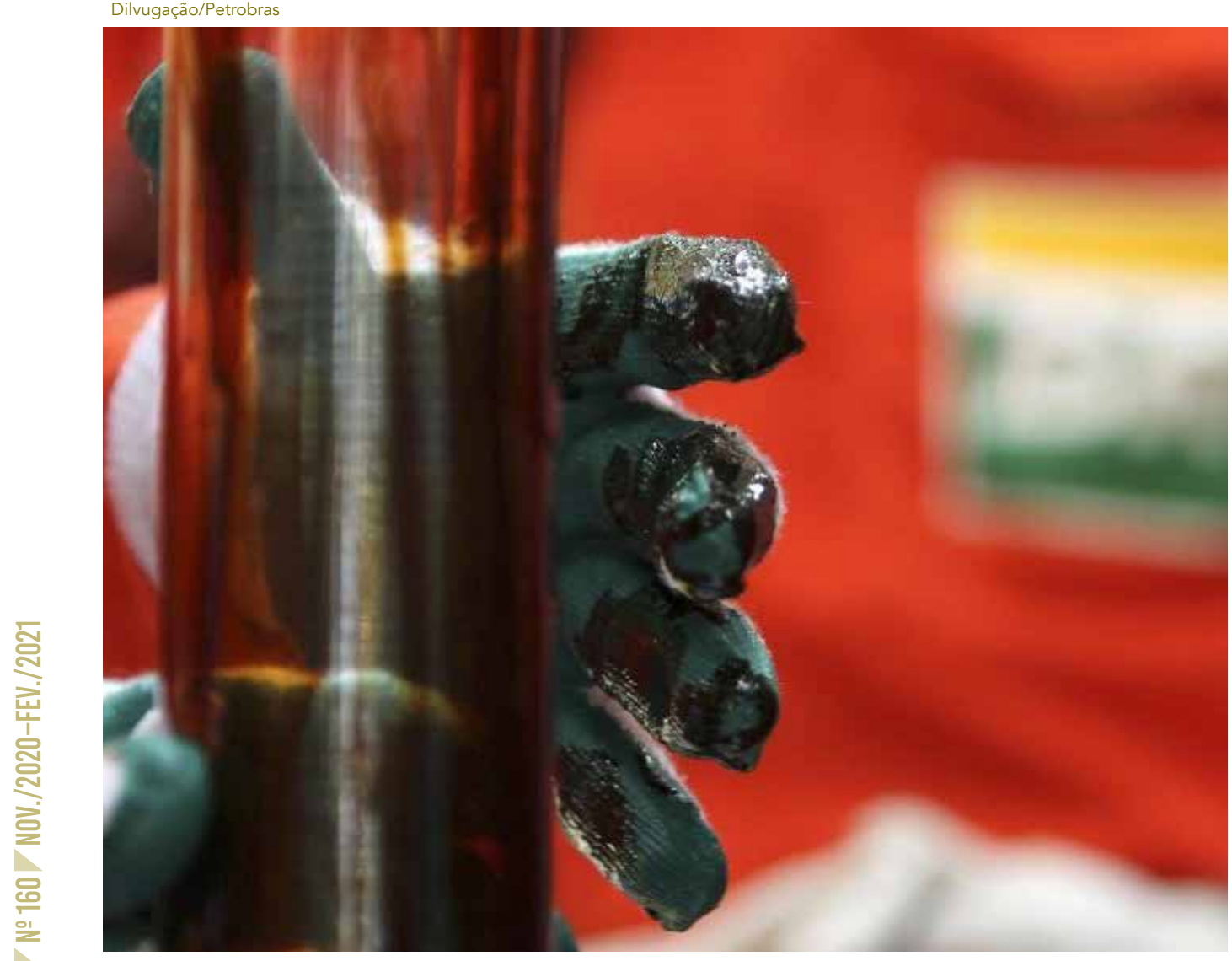

318 


\section{RESUMO}

A Constituição Federal de I988 encampou um projeto de superação do subdesenvolvimento com vistas a alcançar um Estado de bem-estar social. Estabeleceu que a pesquisa e a lavra das jazidas de petróleo são monopólio da União. Definiu a soberania nacional, a redução das desigualdades regionais e sociais e a busca do pleno emprego como alguns dos princípios da ordem econômica. A exploração e produção de petróleo estariam, portanto, vinculadas aos objetivos e princípios da ordem econômica da Constituição Federal. O artigo pretende analisar o impacto das mudanças na legislação que trata das atribuições e tarefas da Petrobras na exploração do petróleo nas áreas do pré-sal. A lei $\mathrm{n}^{\circ}$ I3.365/20I6 modificou o contrato de partilha e reduziu o papel da Petrobras na exploração do pré-sal. Podemos estar diante de mais uma tentativa de bloqueio das chamadas cláusulas transformadoras da Constituição e da entrega de nossas riquezas naturais aos interesses de empresas multinacionais e de outros países. Tal situação pode impor novas tarefas ao direito econômico, diante dos riscos e ameaças à soberania e do bloqueio ao desenvolvimento nacional. Pretende-se desvendar o pano de fundo de tais mudanças: a disputa pela apropriação do excedente econômico gerado pela exploração do petróleo nas áreas do pré-sal.

Palavras-chave: Petróleo. Direito econômico. Mercado interno. Política industrial. Excedente econômico.

\section{ABSTRACT}

The Federal Constitution of 1988 encamped a project to overcome underdevelopment with a view to achieving a social welfare state. It established that research and mining of oil deposits are Union monopolies. It defined the national sovereignty, the reduction of regional and social inequalities and the search for full employment as some of the economic order principles. The exploration and production of oil would, therefore, be linked to the objectives and principles of the economic order of the Federal Constitution. This article intends to analyze the impact of changes in legislation that deals with Petrobras' duties and tasks in oil exploration in the pre-salt areas. The Law 13.365/20I6 modified the sharing contract and reduced Petrobras' role in the exploration of the pre-salt. We may be faced with yet another attempt to block the so-called transforming clauses of the Constitution and to the handover of our natural wealth to the interests of multinational companies and other countries. Such a situation would impose new tasks on economic law, given the risks and threats to the sovereignty and the blockade to national development. It is intended to unveil the background of such changes: the dispute for the appropriation of the economic surplus generated by oil exploration in the pre-salt areas.

Keywords: Oil. Economic law. Intern market. Industrial policy. Economic surplus. 


\section{INTRODUCC̣̃O}

Após o anúncio oficial da descoberta de novas reservas de petróleo em território brasileiro, por determinação do então presidente da República Luiz Inácio Lula da Silva o Conselho Nacional de Política Energética (CNPE) editou a resolução no 6/2007, que determinou à Agência Nacional do Petróleo, Gás Natural e Biocombustíveis (ANP) a exclusão de 4I blocos situados na área da província do pré-sal, que foram relacionados na $9^{\text {a }}$ rodada de licitações, e, ao Ministério de Minas e Energia (MME), a elaboração de estudos visando à promoção de mudanças no marco legal do petróleo que salvaguardassem os interesses nacionais no intuito de um melhor aproveitamento desses recursos energéticos recém-descobertos (ANP, 2007).

A Constituição Federal de 1988 (CF/1988) traz em seu artigo $3^{\circ}$ o propósito de implementar um programa de transformações econômicas e sociais a partir de uma série de princípios e objetivos fundamentais de política social e econômica que devem ser observados pelo Estado brasileiro. O sentido da CF/1988 estaria vinculado à concepção da Constituição como um projeto de construção nacional.

O uso dos recursos minerais, especialmente do petróleo, portanto, estaria constitucionalmente vinculado ao objetivo de superação do subdesenvolvimento. Por sua dimensão estratégica, as decisões que envolvem as fontes de energia, em especial o petróleo, estão inseridas no centro da política macroeconômica. O controle soberano do Estado sobre esse processo é a única forma de assegurar que a exploração do petróleo esteja a serviço dos interesses nacionais, sendo inevitável o surgimento de conflitos entre o interesse público e o capital privado. É nesse diapasão que se inserem os estudos sobre os institutos jurídicos adequados para garantir a soberania e prevalência dos interesses da coletividade diante do mercado e dos detentores do poder econômico.

O direito econômico estabelece um referencial teórico e metodológico próprio para essa análise; expressa, também, uma visão interdisciplinar que envolve elementos de economia política, formação histórico-social e debates legislativos na elaboração do regramento legal.

À luz do programa econômico inscrito na CF/1988, que vincula a exploração do petróleo ao cumprimento das cláusulas transformadoras, e especialmente de seu artigo $3^{\circ}$, o objetivo deste artigo é investigar as mudanças no regime jurídico de exploração do petróleo nas jazidas do pré-sal. Tais alterações foram estabelecidas pela lei no I3.365/20I6, que flexibiliza as regras sobre a participação da Petrobras nos consórcios de produção de petróleo nas áreas do pré-sal.

As forças que ora se levantam para retirar a obrigatoriedade de a Petrobras atuar como operadora exclusiva dos campos de petróleo e gás na área do pré-sal (artigos $4^{\text {o; }}$ IO, III, c; I9; 20; e 30, da lei n I2.35I/20IO), são as mesmas que promoveram as reformas constitucionais no Brasil, de corte neoliberal, a partir do início dos anos $1990^{\mathrm{I}}$.

Com a justificativa de viabilizar a inserção do Brasil na economia globalizada,

1 Para mais informações sobre neoliberalismo, vide Anderson (1995). 
tais medidas visavam a um alinhamento do Estado brasileiro ao chamado "Consenso de Washington", programa formulado por instituições financeiras internacionais como o Fundo Monetário Internacional (FMI) e o Banco Mundial, que, dentre outras ações, propunha a liberalização do comércio e dos investimentos estrangeiros e a privatização de empresas estatais (BERCOVICI, 20II).

Diante da crise atual em que a Petrobras foi envolvida, têm surgido inúmeras propostas de reestruturação da empresa e de alterações nos ordenamentos jurídicos que organizam a exploração do petróleo no Brasil. Repetem os argumentos dos que se opunham à criação da Petrobras, em 1953, e dos que promoveram a quebra do monopólio do petróleo, em I995, de que a empresa não teria condições financeiras de arcar com todos os investimentos necessários para a exploração do petróleo na província do pré-sal - que, não obstante, foi descoberta unicamente em virtude de seus investimentos e tecnologia da própria Petrobras (BERCOVICI, 20I6).

Neste artigo partimos da hipótese de que o regime de partilha para a exploração das jazidas de petróleo no pré-sal e em áreas estratégicas, em sua versão original (lei no I2.35I/20IO), reforçaria o papel do Estado brasileiro na definição dos rumos da política energética e da cadeia produtiva da indústria do petróleo - em aproximação ao projeto constitucional de superação do subdesenvolvimento.

Ao reconhecermos o Estado como promotor do desenvolvimento e das transformações sociais, e não apenas regulador da atividade econômica, buscamos analisar de que forma a exploração do petróleo na bacia do pré-sal estaria inserida na mitigação de desigualdades sociais históricas, na garantia do desenvolvimento nacional (artigo $3^{\circ}$, incisos II e III da Constituição Federal), na defesa da soberania e na efetividade dos direitos sociais (BRASIL, I988).

\section{0 REGIME CONSTITUCIONAL DA ATIVIDADE ECONÔMICA PETROLÍFERA}

\section{I. O monopólio da União sobre o petróleo}

No Brasil, o monopólio estatal sobre o petróleo está previsto na Constituição de 1988. Emergiu com a criação da Petrobras, através da lei no 2.004 , de 5 de outubro de 1953. A partir da Constituição de 1967, a matéria passou a residir em disposição dotada de hierarquia máxima do ordenamento jurídico.

A CF/1988, ao atribuir o monopólio das atividades econômicas relativas ao petróleo à União, conferiu a ela, simultaneamente, a correspondente titularidade do recurso mineral e sua comercialização (CLÈVE; MARTINS, 2004).

Entre a sua criação, em 3 de outubro de I953, e a sanção da lei nº 9.478, de I997, a Petrobras exerceu, em nome da União, o monopólio nas áreas de pesquisa, lavra, refino e transporte de petróleo e seus derivados.

Nesse intervalo, entre I953 e I997, o Brasil adotou o modelo de monopólio estatal puro na indústria de petróleo. Como visto, a CF/1988 consagrou o petróleo, os re- 


\section{Dadas as suas características de} fonte de energia estratégica, o petróleo teria ligação direta com o desenvolvimento econômico, sendo a sua exploração relacionada aos objetivos fundamentais do país. "Diante disso, tratou o constituinte de resguardar o desenvolvimento nacional destinando a exploração desse recurso ao atendimento da demanda no mercado interno"

cursos minerais e os bens do subsolo como patrimônio da União (artigos 20, IX, e I76, caput). O legislador constituinte consignou a propriedade, bem como toda a cadeia de refino e comercialização do petróleo, como atividades exclusivas do Estado e exercidas diretamente por ele (art. 177 da CF/1988), o que foi alterado com a EC (emenda constitucional) no $9 / 1995$.

$\mathrm{Na}$ trajetória internacional do petróleo, o papel das companhias privadas foi muito forte e influenciou a geopolítica de diversos países (ROOS, 2013). No entanto, dado o caráter estratégico do petróleo, parte dos países detentores de grandes reservas tem optado por manter o controle estatal sobre estas e também, em muitos casos, delegar a exploração diretamente a empresas públicas².

Para Clève e Martins (2004, p. 45), diante da magnitude econômica e do alcance do petróleo para o interesse coletivo e para o desenvolvimento do país, "esse escasso combustível fóssil pode ser considerado patrimônio nacional irrenunciável”.

$\mathrm{Na}$ década de 1990, com a justificativa de viabilizar a inserção do Brasil na economia globalizada, foram realizadas diversas privatizações nas áreas de petroquímica e fertilizantes pelo presidente Fernando Henrique Cardoso (FHC), por meio da implementação do Programa Nacional de Desestatização (PND) (LEITE, 2007).

Esse tema, de relevante interesse nacional, foi modificado com a promulgação da EC nº 9/1995. Na ocasião, a resistência de importantes parcelas da sociedade à quebra do monopólio petrolífero levou os legisladores a manter o monopólio jurídico

2 "Essa tendência é hoje predominante no mercado mundial. Brasil, China, Rússia, Venezuela, Noruega, Argélia, além de outros importantes produtores do Golfo Pérsico, apesar de terem participação do capital privado, detêm controle sobre suas reservas. A Saudi Aramco (hoje estatal) continua sendo a maior empresa em termos de produção, responsável hoje sozinha por $10 \%$ da produção mundial." (ROOS, 2013, p. 40) 
do Estado, flexibilizando apenas o monopólio do exercício da atividade econômica.

É preciso atinar para a diferença entre o monopólio jurídico e o monopólio econômico (do setor privado). Para Bercovici (20I4, p. I39), "o monopólio estatal é um instrumento da coletividade no moderno Estado intervencionista. Trata-se de uma técnica de atuação estatal, utilizada para realizar determinada tarefa a mando do interesse público." Em outras palavras, a definição de um monopólio está vinculada à realização de uma finalidade pública. O fundamento do exercício e realização do monopólio é a necessária condução estatal da política econômica. Nesse sentido, o monopólio estatal é uma forma especial da economia pública, instituída a partir de considerações da política econômica e de acordo com os dispositivos da constituição econômica e as normas constitucionais instituidoras dos fins do Estado (BERCOVICI, 20I4).

O monopólio estatal implica subtrair da esfera da iniciativa privada a legitimação para o exercício de uma determinada atividade, em virtude do interesse público. A diferença entre monopólio público e monopólio privado estaria relacionada aos objetivos econômicos da função de exclusividade (BERCOVICI, 20I4)3.

O monopólio do petróleo, constitucionalmente tutelado e de titularidade da União, tem uma razão de ser muito clara, ligada à essencialidade e à finitude desse bem. Cada vez mais a complexa relação estabelecida globalmente sobre sua exploração e comercialização é agravada por intervenções bélicas, o que põe em xeque a soberania dos países menos preparados e o desenvolvimento econômico dos países mais dependentes de sua importação (CLÈVE; MARTINS, 2004).

Dadas as suas características de fonte de energia estratégica, o petróleo teria ligação direta com o desenvolvimento econômico, sendo a sua exploração relacionada aos objetivos fundamentais do país. "Diante disso, tratou o constituinte de resguardar o desenvolvimento nacional destinando a exploração desse recurso ao atendimento da demanda no mercado interno" (CLÈVE; MARTINS, 2004, p. 44).

É, portanto, cabal o argumento que vincula a exploração do petróleo aos objetivos fundamentais da República, especialmente os elencados no artigo $3^{\circ}$ da $\mathrm{CF} / \mathbf{1 9 8 8}$. Ao estabelecer o monopólio estatal para a atividade de exploração de jazidas do petróleo, o constituinte atrelou a política petrolífera à constituição econômica (BERCOVICI, 20I4).

\subsection{A emenda constitucional $\mathbf{n}^{\circ}$ 9/1995, a flexibilização do monopólio eco- nômico e a manutenção do monopólio jurídico da União}

A EC no 9/1995 retirou do texto constitucional a Petrobras como executora única do monopólio. No entanto, manteve o monopólio da União sobre o petróleo,

3 "No monopólio de fato, ou natural, a concentração econômica se exacerba em detrimento da livre concorrência, e a ordem jurídica atua no sentido de evitar o abuso de poder econômico decorrente dessa situação, conforme determina o artigo 173, § $4^{\circ}$ da Constituição. O monopólio de direito é criado para a proteção do interesse público, reservando ao Estado a exclusividade daquela atividade econômica. O conceito constitucional de monopólio é de monopólio estatal, ou público, nunca de monopólio privado" (BERCOVICl, 2014, p. 138). 
que passou a ser explorado diretamente ou por meio de empresas estatais ou privadas contratadas ${ }^{4}$.

O entendimento de Moraes (200I) é de que com a EC no 9/1995 foi mantido o monopólio da União sobre a pesquisa e a lavra das jazidas de petróleo e gás, mas ficaria franqueada à União a possibilidade de contratação de empresas estatais ou privadas para a realização dessas atividades. E defende a possibilidade controversa da adoção de um sistema de concorrência para essa atividade 5 .

A EC no 9/1995 teria encerrado o monopólio estatal no exercício da atividade econômica relacionada ao petróleo e gás natural, mantendo, porém, o monopólio da própria atividade. Ou seja, a pesquisa e a lavra das jazidas de petróleo e gás natural continuam constituindo monopólio da União, no sentido de que somente o poder púbico é que poderá decidir, com exclusividade, quem poderá exercer essa atividade econômica. "É ao que nos referimos como monopólio de escolha do poder público" (MORAES, 200I, p. I67).

O monopólio legal de petróleo e gás sempre se configurou como intervenção estatal no domínio econômico por absorção. Dito de outra maneira, o Estado assumiria integralmente a atividade e atuaria como sujeito econômico dos meios de produção nesse setor de atividade econômica (MORAES, 200I).

Para Bercovici (20I4, p. I40), apenas o monopólio estatal do exercício direto das atividades do setor petrolífero foi extinto, sendo preservado o monopólio estatal sobre essas atividades. "O atual regime jurídico-constitucional do petróleo no Brasil é um caso típico de exercício do monopólio estatal com 'quebra de reserva', com a possibilidade de contratação de particulares", afirma o autor.

O monopólio estaria ligado à exclusividade na prestação da atividade econômica ou empresarial, não à propriedade exclusiva dos meios de produção ou à propriedade estatal. A característica essencial do monopólio é a exclusão de outros competidores daquela atividade econômica, denotando um poder amplo de controle sobre a atividade monopolizada (BERCOVICI, 20I4).

Desse modo, mesmo com a EC no 9/1995, a União permaneceu titular do domínio sobre os recursos naturais, inclusive em relação ao petróleo e ao gás natural, já analisado o artigo 20, IX, da CF/I988. Entretanto, a redação atual do parágrafo ${ }^{\circ}{ }^{\circ}$ do artigo I77 permite à União escolher entre a manutenção do sistema de pesquisa e lavra atual ou a adoção de um novo sistema, com a consequente contratação de empresas estatais ou privadas, nos termos da lei (MORAES, 200I).

4 Para Bercovici (2011), a aprovação da EC n 9/1995, por meio dos legisladores ordinários, modificou um dos princípios ideológicos originários estabelecidos pela Assembleia Nacional Constituinte

5 . Posteriormente à aprovação da $E C n^{\circ}$ 9/1995, o Congresso Nacional aprovou, e o então presidente Fernando Henrique Cardoso (FHC) sancionou, a lei $n^{\circ} 9.478$, de 6 de agosto de 1997, que, dentre outras medidas, estabeleceu o regime de concessões (arts. 24, 25, 26, 43, 44 e 45, entre outros) para exploração e produção de petróleo e outros hidrocarbonetos, e criou a Agência Nacional do Petróleo (ANP), autarquia especial vinculada ao Ministério de Minas e Energia (MME) e órgão regulador da indústria do petróleo, gás natural, seus derivados e biocombustíveis (art. $7^{\circ}$, caput). 


\section{A disputa em torno da definição da política de exploração do petróleo no pré- sal e, particularmente, das atribuições da Petrobras nesse processo, repõe os termos do desafio histórico brasileiro, de superação do subdesenvolvimento e da afirmação econômica da soberania nacional - ao mesmo tempo que põe em marcha a articulação de agentes econômicos e políticos vinculados ao setor privado, especialmente as frações de capital estrangeiro, para a definição normativa e institucional favorável aos seus interesses econômicos}

\subsection{Especificidades do direito econômico do petróleo no Brasil}

Na clássica definição de Comparato (1965), "o direito econômico engloba o conjunto de técnicas jurídicas utilizadas pelo Estado na realização de sua política econômica". E a CF/1988 define, com meridiana clareza, que sua política econômica é a que visa à garantia do desenvolvimento nacional (art. $3^{\circ}$, II) e à finalidade de assegurar a todos existência digna (art. I70, caput).

Em que pesem as diferentes visões sobre o tema, haveria um elemento comum entre as diversas concepções de direito econômico: este teria como objeto "a organização jurídica do espaço político-econômico de acumulação" (BERCOVICI, 20I9, p. 470).

O direito econômico, portanto, não é mero reflexo das relações econômicas dominantes, ele é dotado de um caráter contrafático, institucionaliza as relações econômicas, mas também busca transformá-las (OCTAVIANI, 20I4).

As diretrizes constitucionais para a atuação no âmbito do direito econômico são o resultado de objetivos a serem alcançados em matéria de política econômica e expressam o saldo de lutas sociais e embates na definição desses rumos (OCTAVIA$\mathrm{NI}, 2 \mathrm{OI} 4)$.

A CF/I988 é suficientemente clara ao estabelecer objetivos e finalidades do ordenamento jurídico econômico e social. Essa compreensão deve ser vinculada à interpretação de todo o texto constitucional. 
O ceticismo com as aspirações constituintes não supera, entretanto, a atualidade do desafio furtadiano da superação do subdesenvolvimento, mas requer uma problematização pormenorizada das instituições, instrumentos e formas jurídicas contemporâneas destinados a facilitar o desenvolvimento nacional (MASSONETTO, 20I5).

A tarefa do direito econômico brasileiro, de atuar para a garantia do desenvolvimento nacional, requer uma atualização do debate sobre o papel do Estado como "estrutura indispensável da reposição das condições necessárias à reprodução ampliada do capital" (MASSONETTO, 20I5, p. 29).

As volumosas reservas de petróleo sob a camada do pré-sal estão ameaçadas de serem convertidas em um "Distrito Diamantino"6 contemporâneo. A disputa em torno da definição da política de exploração do petróleo no pré-sal e, particularmente, das atribuições da Petrobras nesse processo, repõe os termos do desafio histórico brasileiro, de superação do subdesenvolvimento e da afirmação econômica da soberania nacional - ao mesmo tempo que põe em marcha a articulação de agentes econômicos e políticos vinculados ao setor privado, especialmente as frações de capital estrangeiro, para a definição normativa e institucional favorável aos seus interesses econômicos.

Para Rangel (2012), a peculiaridade da economia brasileira é a dualidade; ou seja, cada instituto ou categoria, o latifúndio, a indústria, o comércio, o capital, o trabalho e a nossa própria economia nacional, deveriam ser observados sob duas perspectivas distintas, mas imbricadas: de como se relacionam no interior (do país) e no exterior (com outros países). Seriam, portanto, mistos, com dupla natureza, e se constituiriam num todo, mas com particularidades próprias em cada âmbito, interno ou externo.

Por aproximação ao raciocínio rangeliano, a forma política estatal e a forma jurídica seriam, portanto, inseridas nesse circuito da dualidade, podendo afigurar coisas diversas se vistas do interior ou do exterior. O que importa dizermos aqui é que o capitalismo se desenvolve de forma distinta no espaço e no tempo e organiza suas formas de acumulação no plano nacional e também no plano internacional, criando dinâmicas integradas e dependentes de circulação e reprodução do capital, interna e externamente (RANGEL, 20I2).

O direito econômico, sob o ponto de vista macrojurídico, estaria voltado para a ordenação do processo econômico, da atividade econômica e da definição de um sistema normativo que organizaria a política econômica estatal. Para Massonetto (2015, p. 3I), "a visão parcial do fenômeno jurídico não revela a ligação estrutural da forma jurídica no processo de valorização do capital”.

O direito econômico no Brasil pode ser tomado como o resultado, em sua forma jurídica, das lutas sociais, de classes, frações de classes, corporações nacionais e estrangeiras que criam um sistema normativo que configura e limita a atuação estatal e do setor privado em relação à economia (OCTAVIANI, 20I4).

6 Instituição sui generis adotada pela Coroa portuguesa em 1771 para controlar a exploração de diamantes no território que abrange a atual cidade de Diamantina, em Minas Gerais. Não havia qualquer relação do Distrito Diamantino com a administração colonial. Um intendente nomeado diretamente por Lisboa gozava de amplos poderes sobre aquele território. lam do confisco de bens à decretação da pena de morte. Vide Prado Jr. (1987). 
Dada a sua historicidade, a ciência econômica varia com o modo de produção, que muda ininterruptamente. A historicidade é, também, um aspecto essencial das leis da ciência social (RANGEL, 20I2). Vimos anteriormente que uma das dimensões investigativas do direito econômico é, mais uma vez, a dimensão histórica (OCTAVIANI, 20I4).

A especificidade do direito econômico do petróleo, portanto, está embasada na investigação histórica e contemporânea das políticas traçadas no país para a exploração do petróleo e dos recursos minerais. No caso brasileiro ela está vinculada, constitucionalmente, aos objetivos e finalidades da ordem econômica e ao projeto nacional de desenvolvimento (BERCOVICI, 20II). Entretanto, é preciso observar as disputas históricas que se organizam no Brasil em torno da questão do petróleo.

Para Rangel (20I2), a ciência social (também a jurídica) deve buscar conhecer as leis que governam a história para poder incidir sobre esse processo. Argumenta que as leis da economia brasileira seriam peculiares. Essas peculiaridades, por sua vez, reforçariam o seu sentido histórico. A tarefa do pesquisador seria "pôr em ordem os termos da equação", provendo-nos de um "conhecimento ordenado e sistematizado, que nos torne capazes não apenas de prever a marcha dos acontecimentos, mas nela intervir para dirigir o processo" (RANGEL, 2012, p. 297) ${ }^{7}$.

Desde a criação da Petrobras, em I953, até os dias atuais, essa história tem sido marcada por movimentos pendulares, que ora tendem para uma orientação soberana e voltada para a internalização dos centros decisórios (BERCOVICI, 20II), ora pendem para a subordinação econômica aos interesses privados e/ou externos.

O estudo do direito econômico do petróleo compreende, portanto, o regime jurídico-constitucional acerca dos recursos minerais e do petróleo e a análise da política de exploração adotada em face do sentido do projeto constitucional de desenvolvimento nacional autônomo.

\section{PETRÓLEO, SOBERANIA E DESENVOLVIMENTO: OS RISCOS E AMEACSAS PROVOCADOS PELA LEI № $13.365 / 2016$}

\section{I. Aspectos controversos da lei $n^{\circ}$ 13.365/2016}

Diante da crise atual envolvendo a Petrobras, têm surgido propostas de reestruturação da empresa estatal e de alterações nos ordenamentos jurídicos que organizam a exploração do petróleo no Brasil. As ideias que mobilizam tais propostas

\footnotetext{
"As leis da economia brasileira são, em certo sentido, próprias, peculiares. As diferentes economias que nela coexistem não se justapõem mecanicamente. Ao contrário, agem uma sobre as outras, achamse em constante conflito, a ver qual imporá sua dinâmica específica ao sistema. Noutros termos, estão em unidade dialética, unidade de contrários. [...] A resultante não é nem um nem outro dos termos em conflito, mas um sistema original, dotado de uma dinâmica própria. Mudam os termos em conflito - e a história dessa mudança é o que há de específico na história do Brasil —, embora o próprio conflito continue" (RANGEL, 2012, p. 297). A história da regulamentação da exploração do petróleo no Brasil poderia ser perfeitamente enquadrada nessa "dinâmica própria" da economia brasileira: são sucessivos e repetitivos conflitos, cujo pano de fundo é a disputa pela acumulação do excedente econômico produzido por essa atividade.
} 
lembram os argumentos dos que se opunham à criação da Petrobras, em I953, e dos agentes políticos que promoveram a quebra do monopólio do petróleo, em 1995.

Sob o pretexto de defesa dos interesses nacionais, a retirada da participação da Petrobras na exploração do petróleo no pré-sal afronta o princípio constitucional da soberania econômica, por retirar das mãos do Estado brasileiro a decisão sobre como e quando explorar esse importante recurso energético que é o petróleo. As imensas jazidas de petróleo localizadas na região do pré-sal permitem que a Petrobras planeje com segurança e garantia seus investimentos em exploração e produção de óleo e gás ${ }^{8}$.

O projeto de lei do Senado (PLS) no ${ }^{\circ}$ 3I/2015, de autoria do senador José Serra (PSDB-SP), agora aprovado e convertido na lei $\mathrm{n}^{\mathrm{o}} \mathrm{I} 3.365$, de 29 de novembro de 2016 , sintetiza o pensamento político reacionário, renega o caráter estratégico e soberano do petróleo e advoga pela entrega da propriedade e da gestão do petróleo às multinacionais do setor. Como veremos adiante, os argumentos contidos na exposição de motivos do PLS nº I3I/20I5 são uma atualização dos argumentos de fundo liberal e não nacionalistas que foram contrários à criação da Petrobras e do monopólio da União sobre o petróleo ${ }^{9}$.

Esses argumentos menosprezam a capacidade estatal de produção, gestão e investimento tecnológico e ainda vão na contramão do movimento internacional de estatização que vem sendo feito por países detentores de grandes reservas ${ }^{10}$.

O PLS no 131/20I5, aprovado em definitivo na Câmara dos Deputados em II de novembro de 2016 e sancionado no dia 29 de novembro de 2016 (lei no $13.365 / 2016$ ), revoga e/ou modifica os seguintes dispositivos da lei $n^{\circ}$ I2.35I/20IO: arts. $2^{\circ}, 4^{\circ}, 9^{\circ}$, IO, I4, I5, 20 e 30. Tais alterações, em suma, retiram a previsão sobre a participação mínima da Petrobras no consórcio de exploração no pré-sal e revogam a definição de que a Petrobras atuasse como operadora, obrigatoriamente, em todos os campos do pré-sal e áreas estratégicas.

Na exposição de motivos do PLS no I3I/20I5 (BRASIL, 20I5), podem-se encontrar, em síntese, os seguintes argumentos:

I. "primeiramente, a exploração do pré-sal tem urgência, pois a oferta interna de petróleo em futuro próximo dependerá dessa exploração, sobretudo a partir de 2020";

8 Para D'Almeida, "uma empresa produtora de petróleo vive de produzir petróleo e de buscar repor suas reservas" (D'ALMEIDA, 2015).

9 Sobre os debates acerca da criação da Petrobras: "Pesou, ainda, no apoio à adoção do monopólio estatal, a participação, nos estados, de guarnições militares que participavam mais ativamente da 'campanha do petróleo', favoráveis às posições nacionalistas. De outro lado, segmentos da sociedade de tendência política liberal posicionaram-se contra a criação de uma companhia estatal de petróleo, pois consideravam inviável a implantação no Brasil de uma indústria complexa como a do petróleo, completamente integrada, como estava sendo proposto pelos grupos nacionalistas, em razão da falta de tecnologia, de capacidade empresarial e de pessoal técnico em condições de levar adiante os grandes empreendimentos nas diversas fases da cadeia produtiva do petróleo" (MORAIS, 2013, p. 272).

10 Sobre a nacionalização das reservas de petróleo, ver Morais (2013): "Como resultado dos processos de nacionalização citados, a atual estrutura de propriedade das reservas de petróleo mundiais não deixa dúvidas quanto ao peso dos governos no setor: das 25 maiores empresas de petróleo no mundo, 18 são estatais; aproximadamente $90 \%$ das reservas mundiais de petróleo e $75 \%$ da produção são controladas por empresas estatais" (MORAIS, 2013, p. 273). 


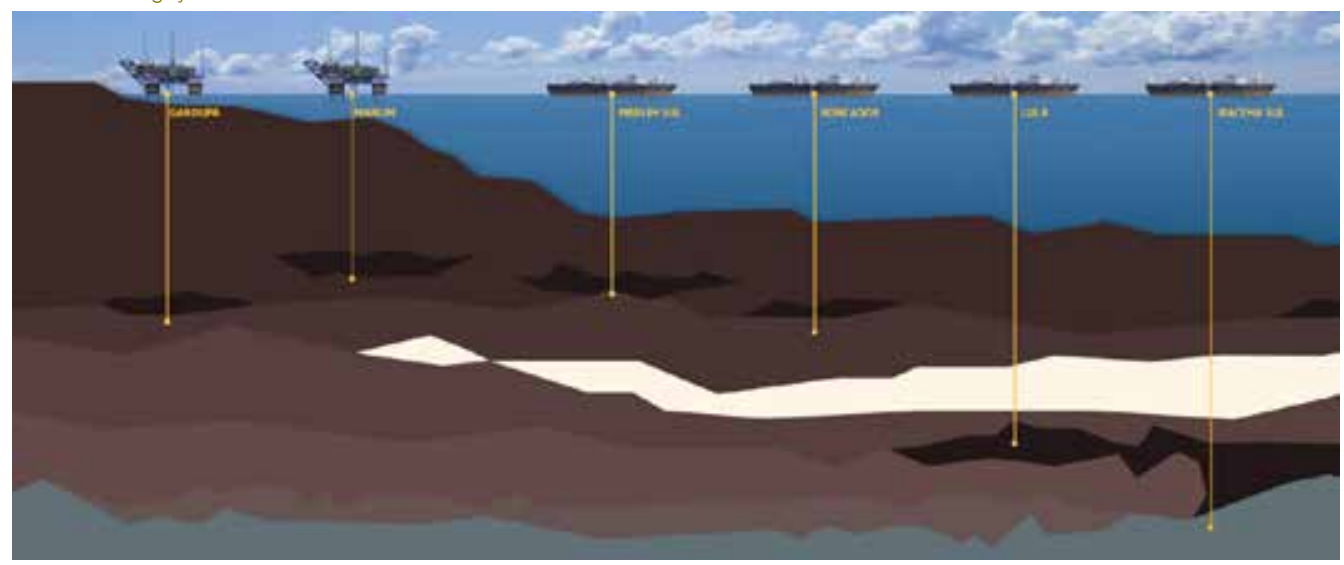

A descoberta do pré-sal foi possível em decorrência dos investimentos e acúmulo técnico-científico da Petrobras ao longo de muitos anos

2. as investigações da Justiça que recaem sobre a empresa teriam gerado nesta uma desordem de gestão organizacional. Essas ações também criariam uma dificuldade para a empresa obter financiamento externo. Aponta-se uma incapacidade de investimento da Petrobras na exploração do petróleo devido à crise jurídica em que ela se encontraria imersa;

3. a queda do valor internacional do petróleo poderia inviabilizar a exploração do pré-sal, dados os altos custos envolvidos nessa operação;

4. "são imprescindíveis as alterações previstas na presente lei com vistas ao restabelecimento de um modelo que garanta a exploração ininterrupta e maiores possibilidades de ganhos para o Tesouro Nacional”.

$\mathrm{O}$ primeiro argumento, segundo o qual se justificaria a retirada da participação obrigatória da Petrobras no pré-sal dada a urgência da exploração do petróleo "em um futuro próximo" mostra-se completamente esvaziado. Isso quando se observam os dados sobre o exponencial aumento das reservas e da capacidade nacional de produção de petróleo após a descoberta do pré-sal, a implementação da participação obrigatória da Petrobras e a adoção do regime de partilha" ${ }^{\text {II }}$

A descoberta do pré-sal foi possível em decorrência dos investimentos e acúmulo técnico-científico da Petrobras ao longo de muitos anos.

Quanto aos argumentos que afirmam que "as investigações da Justiça sobre negócios da Petrobras [...] têm afetado a estatal, gerando cancelamentos, atrasos e de-

11 Sobre a evolução da produção de petróleo no mercado mundial: "Um retrato real da evolução das atividades petrolíferas no Brasil deve levar em conta, ainda, algumas comparações internacionais para se avaliar a posição do país em relação à evolução mundial. No período de 2000 a 2011, enquanto as reservas brasileiras provadas de petróleo cresceram, cumulativamente, $78 \%$, as reservas de importantes países produtores não pertencentes à Organização dos Países Exportadores de Petróleo (Opep) decresceram ou apresentaram baixo crescimento, como nos casos seguintes: Estados Unidos (aumento de 1,6\%), Noruega (redução de 39\%), Reino Unido (redução de 41\%), México (redução de 44\%). Quanto à produção, o Brasil obteve aumento de 73\% de 2000 a 2011, comparado com aumento de $1,4 \%$ dos Estados Unidos e quedas de 39\% na Noruega, de 59\% no Reino Unido e de 53\% no México. Comparando com a China, verifica-se que as reservas conhecidas desse país não aumentaram, permanecendo em torno de 15 bilhões de barris entre 2000 e 2011, enquanto a produção de petróleo cresceu 26\%" (MORAIS, 2013, p. 275). 
sorganização de suas atividades" (BRASIL, 20I5), nota-se que rememoram os argumentos contrários à criação da própria empresa, questionando sua capacidade técnica e de gestão. Além de todo o reconhecimento internacional (PETROBRAS, s.d.) da empresa mais premiada do Brasil, Morais (2013, p. 264) desmonta as dúvidas sobre a capacidade técnico-gerencial, apontando em suas análises, em forma de síntese, cinco pontos básicos como fatores para o sucesso da Petrobras:

I. política permanente de formação e capacitação de recursos humanos de alto nível para a atuação em atividades operacionais e em pesquisas e desenvolvimento (P\&D);

2. investimentos continuados no centro de pesquisas (Cenpes), voltado ao atendimento das demandas tecnológicas para a produção de petróleo em águas profundas e das demais demandas tecnológicas da companhia;

3. adoção de programas abrangentes de pesquisas e desenvolvimento (Procap I.000, 2.000 e 3.000), voltados ao aprimoramento da capacidade técnica para a exploração e a produção de petróleo em águas profundas, em colaboração com universidades, institutos de pesquisa e empresas fornecedoras de equipamentos e serviços;

4. incentivos à implantação no Brasil de uma rede de empresas fabricantes de equipamentos para a produção de petróleo em águas profundas;

5. incorporação de riscos econômicos e tecnológicos nas decisões de investimentos na exploração e produção de petróleo em águas profundas e ultraprofundas.

Diante dos argumentos que questionam a capacidade de investimento da Petrobras e ainda a viabilidade econômica da empresa, supostamente comprometida pela volatilidade do preço do petróleo no mercado internacional e seus efeitos nos royalties, assevera-se que devido à natureza vultosa e estratégica de tais investimentos, historicamente sempre foi o Estado brasileiro o principal responsável por fazer os aportes financeiros para a exploração do petróleo.

A argumentação econômico-política utilizada como justificativa para a alteração do regime legal de exploração do petróleo não guarda coerência em face dos resultados econômicos apresentados pela exploração do pré-sal na vigência do regime de partilha e da participação obrigatória da Petrobras.

Ademais, a exploração do petróleo como bem de uso especial para a União deve, portanto, se relacionar aos objetivos fundamentais presentes na ordem econômica da CF/I988, cuja promoção da autonomia científica e tecnológica cumpre papel estratégico com vistas à efetividade do desenvolvimento econômico e social e ao cumprimento do programa transformador que dirige teleologicamente a carta constitucional do país.

As mudanças a serem implementadas pela lei $\mathrm{n}^{0} \mathrm{I3} \cdot 365 / 20 \mathrm{I} 6$, portanto, irão fragilizar a atuação da Petrobras na exploração e produção de petróleo no pré-sal, 
bem como o seu papel de coordenação e indução do desenvolvimento industrial brasileiro.

Não faz o menor sentido compreender o direito econômico como axiologicamente "neutro" ou meramente técnico. Para Bercovici (20II, p. 3I6), "a defesa da exploração dos recursos minerais e petrolíferos por empresas privadas é feito por motivos ideológicos e financeiros, com afirmações sem comprovação histórica ou empírica”.

De fato, não se pode abrir mão do papel do Estado na definição dos rumos da política energética e da política sobre a exploração do petróleo e dos recursos minerais. O marco estabelecido com o regime de partilha (lei $\mathrm{n}^{\circ} \mathrm{I} 2.35 \mathrm{I} / 20 \mathrm{IO}$ ) para a exploração das jazidas na área do pré-sal reforçaria o papel do Estado brasileiro na definição dos rumos da política energética e da cadeia produtiva do petróleo.

Assim, entende-se, em síntese, que a lei no $13.365 / 2016$ enfraquece a participação da Petrobras na exploração do petróleo no pré-sal em benefício das grandes multinacionais estrangeiras. Tais mudanças põem em xeque a soberania econômica, dada a importância da Petrobras e da cadeia industrial do petróleo e gás para a economia do país.

\subsection{Petróleo e soberania}

A soberania econômica nacional, prevista formalmente no artigo I70, I da CF/1988, "visa viabilizar a participação da sociedade brasileira, em condições de igualdade, no mercado internacional, como parte do objetivo maior de garantir o desenvolvimento nacional, buscando a superação do subdesenvolvimento" (GRAU, 2000, p. 225).

A formação social e econômica brasileira esteve completamente voltada para a extração de recursos naturais e primários para o abastecimento do comércio exterior. O Brasil, outrora colônia, atualmente república, se formou economicamente como uma economia dependente e periférica, sempre sob forte influência do capital externo $^{\mathrm{I2}}$.

Mudam-se os tempos, as instituições, as formas de dominação, mas prevalece no capitalismo contemporâneo a relação centro-periferia, outrora metrópole-colônia. Não vencemos por completo a herança colonial, que foi implacável em impedir qualquer ação que buscasse o progresso econômico e material nacional.

As tentativas de industrialização foram sufocadas e bloqueadas. Somente com a Revolução de 1930 iniciou-se um projeto consciente de implantação de um par-

12 Sobre a formação econômica do Brasil: "A situação de dependência e subordinação orgânica e funcional da economia brasileira com relação ao conjunto internacional de que participa é um fato que se prende às raízes da formação do país. [...] Economia de exportação, constituída para o fim de fornecer gêneros alimentícios e matérias-primas tropicais aos países e populações das regiões temperadas da Europa e mais tarde também da América, ela se organizará e funcionará em ligação íntima e estreita dependência do comércio ultramarino em função do qual se formou e se desenvolveu. Será essencialmente uma economia colonial, no sentido mais preciso, em oposição ao que denominamos de economia nacional, que seria a organização da produção em função das necessidades próprias da população que dela participa" (PRADO JR., 1987, p. 54). 
que industrial no país, condição esta essencial para a formação de um mercado interno de massas, com base em trabalho bem remunerado para a classe trabalhadora e na inserção soberana do Brasil na economia internacional.

É que a soberania nacional - assim como os demais princípios elencados nos incisos do artigo I70 - consubstancia, concomitantemente, um instrumento para o fim de assegurar a todos existência digna e objetivo particular a ser alcançado. Assume a feição de diretriz — norma-objetivo — dotada de caráter constitucional conformador (GRAU, 2000).

Afirmar a soberania econômica nacional como instrumento para realização do fim de assegurar a todos existência digna e como objetivo particular a ser alcançado é definir um programa de políticas públicas voltadas não ao isolamento econômico, mas a viabilizar a participação da sociedade brasileira, em condições de equidade, no mercado internacional.

Controle estatal e atuação estatal direta sobre a exploração dos recursos minerais e energéticos são fundamentais, pois o aproveitamento adequado desses recursos é condição para impulsionar o desenvolvimento. $\mathrm{O}$ controle do Estado sobre eles está vinculado à própria afirmação da soberania econômica ${ }^{13}$.

A exploração do petróleo, portanto, constitui um elemento-chave para a promoção do desenvolvimento autônomo do país. Os recursos minerais deveriam ser redirecionados para o desenvolvimento do mercado interno e para a industrialização. $\mathrm{O}$ que significaria a concretização da nossa soberania econômica.

\subsection{Indústria petrolífera, mercado interno e inovação tecnológica}

$\mathrm{O}$ artigo 219 da $\mathrm{CF} / \mathrm{I} 988$ dispõe expressamente que o mercado interno integra o patrimônio nacional e está articulado à viabilização do desenvolvimento cultural e socioeconômico, do bem-estar da população e da autonomia tecnológica do país.

A integração do mercado interno ao patrimônio nacional se daria na medida em que a Constituição o toma como expressão da soberania econômica nacional.

Os artigos 218 e 219 determinariam a "endogenização" da tecnologia e a homogeneização social, compondo o quadro de internalização dos centros decisórios (OCTAVIANI, 20I3), que deveria também orientar a política econômica da atividade petrolífera.

O incentivo ao mercado interno estaria, portanto, voltado à viabilização da distribuição de renda e à materialização de políticas de bem-estar.

A exploração do petróleo nas jazidas do pré-sal, portanto, também deveria estar vinculada à valorização do mercado interno, pois essa atividade guardaria a

13 Bercovici repõe os termos do papel da soberania na exploração do petróleo no pré-sal: "Soberania econômica, em uma democracia verdadeira, é sinônimo de soberania popular. Soberania econômica e soberania popular não significam apenas que o poder emana do povo, mas também que esse povo tem direito à terra, tem direito aos frutos do seu trabalho e tem direito ao excedente produzido pela exploração dos recursos naturais, que são públicos, portanto, de titularidade do povo, bem como ao direito de decidir por si mesmo sobre o seu presente e sobre o seu futuro" (BERCOVICI, 2011, p. 360). 


\section{Há forte correlação}

entre as políticas de

exploração do petróleo, de

industrialização nacional e

de inovação tecnológica,

com vistas à superação do

subdesenvolvimento nacional.

Tais políticas dificilmente

seriam exitosas sem a

coordenação estatal liderando

esse processo em articulação

com o setor privado

possibilidade de alavancar investimentos em equipamentos, instalações, recursos humanos, pesquisa e desenvolvimento (P\&D) e inovação, e seria a base da política de conteúdo local, que tem potencial de mobilização e articulação para criar um ciclo virtuoso de industrialização no país, promovendo o melhor aproveitamento do excedente econômico produzido com a exploração do petróleo no pré-sal ${ }^{14}$.

Há forte correlação entre as políticas de exploração do petróleo, de industrialização nacional e de inovação tecnológica, com vistas à superação do subdesenvolvimento nacional. Tais políticas dificilmente seriam exitosas sem a coordenação estatal liderando esse processo em articulação com o setor privado.

Foi com base em suas pesquisas e utilizando sua própria tecnologia que a Petrobras, pioneira na exploração de petróleo em águas marinhas, encontrou e perfurou o primeiro poço de petróleo em águas rasas no Brasil, em 1968, a apenas 30 metros de profundidade, até chegar ao descobrimento das jazidas do pré-sal, em 2007, a mais de 7 mil metros de profundidade, em águas ultraprofundas (D'ALMEIDA, 20I5).

A indústria petroleira do Brasil, para alcançar o desenvolvimento sustentável e competitivo, deveria priorizar o setor de refino, o qual agrega valor ao produto final, e, simultaneamente, investir os recursos excedentes de modo a financiar o desenvolvimento de novas tecnologias, incluindo as energéticas (LIMA, 20I4).

Sabemos que no Brasil a indústria pesada, a siderurgia, surgiu com a indústria estatal. Essa é outra particularidade da história do Brasil. A industrialização surge

14 Para Bercovici (2011, p. 356), "a política de desenvolvimento e exploração econômica dos recursos minerais brasileiros deve estar voltada para o mercado interno, sendo fundamental para o próprio parque industrial instalado no país". 
aqui como um componente forte do Estado, que depois viria a ser torpedeado. Quer dizer, o nosso desenvolvimento já comportou uma intervenção estatal, num sentido que não era socialista, mas que não era a forma liberal do crescimento da indústria (MORAIS, 20I3, p. I36).

A exploração do petróleo do pré-sal poderia ser uma excelente oportunidade para o Brasil avançar em políticas de desenvolvimento econômico e de redução das desigualdades regionais e sociais. O ritmo de exploração das jazidas do pré-sal deveria corresponder à capacidade de fornecimento de bens e serviços nacionais, resguardado o abastecimento nacional ${ }^{15}$ (D'ALMEIDA, 20I5, p. I83).

A política de conteúdo local produziu resultados significativos na indústria naval até o final da primeira década dos anos 2000. O Programa de Modernização e Expansão da Frota (Promef), lançado em 2004, encomendou a construção de 49 navios e 20 comboios hidroviários, com investimentos que ultrapassam os R \$ II bilhões. No Promef, os navios têm índice de nacionalização de $65 \%$ na primeira etapa (lançada em 2005, com 26 unidades) e 70\% na segunda (lançada em 2008, com 23 unidades). São navios do tipo Suezmax, Aframax, Panamax, gaseiros, aliviadores com processo dinâmico, de produtos e de transporte de bunker (D'ALMEIDA, 20I5, p. I83).

Consideramos que a política industrial deveria ser ativa e abrangente, focada nos setores ou atividades industriais indutores de mudanças tecnológicas, que geram mais valor. O papel do Estado é fundamental para criar um ambiente econômico e institucional que conduza a evolução das estruturas de empresas, indústrias e a organização institucional, assim como leve à criação de um sistema nacional de inovação, sendo esta última a força motora do desenvolvimento (BARBI; SILVA, 2008).

Dado o volume das atuais reservas de petróleo no Brasil, o país teria em suas mãos a possibilidade de coordenar a exploração e produção de óleo e gás, com a ampliação da capacidade de refino e a expansão da indústria petroquímica e dos fornecedores locais de bens e serviços. Essa política industrial poderia preencher uma lacuna histórica na estratégia nacional de desenvolvimento (BARBI; SILVA, 2008).

Apesar de sofrer constante ataque, a política de preferência pela aquisição de bens e serviços no mercado interno possui amparo legal e tem demonstrado eficácia satisfatória em seu papel de promoção da indústria e da inovação tecnológica ${ }^{16}$.

O poder público poderia, em determinadas circunstâncias, dar preferência à

15 "A Petrobras tem sido um instrumento do Estado, atuando no controle do fluxo comercial com o exterior (gerando economia de divisas com sua produção); gerando empregos e estimulando, por substituição de importações, o crescimento da indústria privada nacional, especialmente a de bens de capital, naval e de serviços de engenharia; desenvolvendo - sozinha ou em cooperação com universidades — tecnologias industriais, ambientais e gerenciais; atraindo investimentos e gerando receita tributária" (D'ALMEIDA, 2015, p. 191).

16 Bercovici (2014) critica a visão segundo a qual se buscaria circunscrever as políticas de incentivo à inovação às regras do direito concorrencial: "As afirmações comuns do debate do direito concorrencial não podem ser aplicadas com sucesso para a análise das singularidades de uma empresa de proporções gigantescas, favorecida pelo monopólio legal do petróleo, e, ao mesmo tempo, destinatária e realizadora dos grandes empreendimentos no campo da inovação da história recente do Brasil" (BERCOVICl, 2014, p. 147). 
aquisição de bens ou serviços de empresas brasileiras que desenvolvam tecnologia. $\mathrm{O}$ sentido dessa preferência se justificaria diante da contribuição ao processo de inovação da economia nacional ${ }^{17}$.

A política de conteúdo local tem sido atacada por economistas ortodoxos ultraliberais, contaminada pelos reflexos da chamada Operação Lava Jato e também passou a ser questionada em órgão de controle, como o Tribunal de Contas da União (TCU).

No mês de junho de 2016 o Tribunal de Contas da União fez uma auditoria e concluiu que a política de conteúdo local seria danosa à Petrobras (CAMAROTTO; JUBÉ, 20I6). Para Bercovici (20I6), o TCU seria um órgão incompetente para avaliar uma política industrial e nem sequer saberia o que é uma política de desenvolvimento (NASSIF, 20I6).

Estima-se que em poucos anos o Brasil estará produzindo grande volume de petróleo e gás natural, especialmente na camada do pré-sal. Entretanto, a produção em grande volume transformaria o Brasil em um mero exportador de petróleo, o que, em vez de contribuir para o desenvolvimento do país, pode trazer problemas à economia nacional se o ritmo exploratório não for bem planejado. A exportação excessiva de recursos minerais poderia levar à sobrevalorização da moeda nacional, o que prejudicaria a competitividade da indústria nacional.

De acordo com Bielschowsky (I988, p. 77), "o desenvolvimentismo foi a ideologia econômica de sustentação do projeto de industrialização integral, considerada como forma de superar o atraso e a pobreza brasileiros". Logo, a tarefa fundamental da superação do subdesenvolvimento seria a industrialização.

A magnitude das reservas e a qualidade do petróleo do pré-sal têm atraído a atenção não apenas das multinacionais de petróleo e gás, mas também dos principais fornecedores de bens e serviços para o setor. Essa seria, portanto, uma grande oportunidade para o país se tornar um polo de fornecimento mundial de bens e serviços para a indústria de petróleo e gás natural.

\section{CONSIDERAÇÕES FINAIS}

A aprovação da lei $n^{\circ}$ 13.365/20I6 sinaliza para medidas liberalizantes nos campos macro e microeconômico. Diferentemente do que alardeiam os defensores das políticas neoliberais, a redução da participação estatal na política de exploração do petróleo não visa a uma maior eficiência ou a apoiar a retomada do crescimento

17 Para Mazzucato (2010, p. 256) o papel do setor público nas políticas de inovação não pode se restringir a apenas incentivar as inovações desenvolvidas pelo setor privado: "Principalmente, mas não apenas, diante da crise recente, não se leva em consideração que a principal força empreendedora veio do Estado e não do setor privado [...]. Foi durante o pós-guerra (Segunda Guerra Mundial) que - Pentágono trabalhou em estreita colaboração com outras agências de segurança nacional, como a Comissão de Energia Atômica e a Agência Especial Americana (Nasa). A colaboração entre as agências levou ao desenvolvimento de tecnologias como computadores, jatos, energia nuclear civil, lasers e biotecnologia". 
econômico; está relacionada diretamente com a abertura de mais espaço para a penetração do capital privado, especialmente estrangeiro, em áreas estratégicas para o desenvolvimento nacional.

O aparecimento desses projetos, que modificaram o regime de partilha, deu-se de forma oportunista em um momento de fragilidades passageiras para a Petrobras. Além das injunções internas, fatores externos também contribuíram para o fortalecimento do discurso ideológico que visa enfraquecer a empresa e seu papel na economia nacional, no geral, e na indústria do petróleo, em particular.

A estagnação econômica dos últimos sete anos provocou a redução das taxas de crescimento do consumo de petróleo e derivados, influenciando também na queda do preço do barril de petróleo no mercado internacional.

$\mathrm{O}$ argumento de que a retirada da Petrobras da condição de operadora única poderia acelerar o ritmo de exploração do petróleo no pré-sal, apresentado como uma das alternativas para a retomada da atividade econômica, não encontra correspondência na realidade.

O principal objetivo da exploração de petróleo no Brasil e da atuação da Petrobras deve ser o abastecimento do mercado interno nacional com petróleo e seus derivados, assegurando energia de boa qualidade e a preços baixos, além da integração da indústria do petróleo ao mercado nacional, com extensa rede de prestadores de serviços, bens, materiais, indústria e recursos humanos qualificados. Em outras palavras, a exploração do petróleo no pré-sal e as atribuições designadas à Petrobras deveriam estar direcionadas ao esforço de superação do subdesenvolvimento nacional.

Na redação original da lei n ${ }^{\circ}$ 12.35I/20IO, a Petrobras, como regra geral, atuaria como operadora de todos os blocos no pré-sal e em áreas estratégicas e poderia ser contratada diretamente pela União, ou em consórcio com empresas privadas através dos leilões de licitação de blocos, ressalvada a participação mínima obrigatória da Petrobras, de 30\%. A Petrobras assumiria tarefas e atribuições que extrapolam a função de uma empresa voltada meramente a produzir petróleo e distribuir lucros. $\mathrm{O}$ regime de partilha definiu uma série de políticas voltadas ao incentivo à produção de conteúdo local e à industrialização nacional, e a Petrobras, enquanto instrumento de atuação econômica do Estado, deveria estar no centro dessa política. A regra geral passa então a ser a definição do operador nos leilões de áreas exploradas, e a exceção, consumada pelo direito de preferência.

Uma estatal é menos propensa a agir com irresponsabilidade na política de exploração predatória, que suscita riscos severos de acidentes ambientais. $\mathrm{O}$ regime de concessões traz prejuízos à coletividade. O ritmo de exploração é definido pela empresa concessionária, que terá melhores resultados financeiros ao extrair a maior quantidade de óleo no menor tempo possível.

Os esforços para a industrialização do país não encontraram obstáculos apenas internos, quase sempre se chocaram com interesses de capitais estrangeiros e de multinacionais. A não retomada do desenvolvimento está ligada à crise do Estado 
brasileiro. A revisão dos instrumentos jurídicos, fiscais e financeiros do Estado deve ser dirigida para a rearticulação do projeto nacional de desenvolvimento.

O fortalecimento das instâncias democráticas e da sua prevalência em relação ao mercado e ao poder econômico privado se articula ao projeto nacional de desenvolvimento. O Estado democrático será incapaz se não for dotado de uma sólida base de poder econômico próprio. Portanto, entendemos que o interesse nacional e da coletividade deve estar em primeiro lugar na decisão sobre o uso do excedente econômico gerado pela exploração de petróleo e recursos minerais. No Brasil, essa disputa tem assumido contornos dramáticos.

A Petrobras não foi criada apenas para prover o abastecimento nacional de petróleo e seus derivados. É a forma empresarial encontrada para alcançar o desenvolvimento econômico e promover os interesses da coletividade. A Petróleo Brasileiro S.A. dirigiu o processo de industrialização nacional e organizou o desenvolvimento de uma rede de fornecedores de bens e serviços. É a grande compradora nacional.

É importante considerarmos que, a pretexto do justo e necessário combate à corrupção, está sendo operado um desmonte sem precedentes da Petrobras e das principais empresas de infraestrutura do país, acarretando enormes prejuízos à coletividade. Dadas as características da indústria do petróleo e a manutenção da forma de contratação por parte da Petrobras para grandes projetos de infraestrutura, o máximo que se pode alcançar é a destruição de determinados agentes econômicos para que outros, especialmente estrangeiros, ocupem o seu lugar.

Entendemos que a Petrobras deveria retomar a orientação da política industrial brasileira, utilizando seu poder de compra e de valorização do mercado interno. Ao mesmo tempo poderia instituir formas eficientes de combate ao cartel das grandes empresas prestadoras de serviços de engenharia e construção, reassumindo a gestão dos empreendimentos, reduzindo o tamanho dos contratos e ampliando a base de fornecedores de bens e serviços.

O estado da arte atual abre o ensejo para novos desafios ao direito econômico do petróleo, num momento em que princípios organizadores da ordem econômica e social da Constituição de I988, assim como o regime constitucional da atividade petrolífera, são colocados em xeque, nos situando cada vez mais distantes da superação do subdesenvolvimento. Consideramos que a luta por um projeto nacional de desenvolvimento e especialmente a persecução dos objetivos estabelecidos no artigo $3^{\mathrm{o}}$ da Constituição Federal continuam atuais e necessárias, entretanto, a tarefa de empreendê-las tornou-se mais difícil e complexa.

* Mestre em Direito Político e Econômico pela Universidade Presbiteriana Mackenzie, professor do curso de Direito da Universidade Nove de Julho e doutorando em Direito pela Pontifícia Universidade Católica de São Paulo (PUC-SP).

Texto recebido em dezembro de 2020; aprovado em dezembro de 2020. 
ANDERSON, Perry et al. A trama do neoliberalismo: mercado, crise e exclusão social. In: GENTILI, Pablo; SADER, Emir (Org.). Pós-neoliberalismo: as políticas sociais e o Estado democrático. Rio de Janeiro: Paz e Terra, 1995. p. 139-180.

ANP. Balanço da gestão da ANP: 2003-2011. Rio de Janeiro: ANP, 2011.

. Resolução CNPE n 6, de 8/11/2007. Diário Oficial da União, Brasília, p. 21, 14 nov. 2007. Disponível em: <http://legislacao.anp.gov.br/?path=legislacao-federal/resolucoes/resol=-cnpe2007/\&itemrcnpe-6--2007>. Acesso em: 3 dez. 2020.

BARBI, Fernando Carvalhaes; SILVA, Ana Lúcia Pinto da. O petróleo do pré-sal: os desafios e as possibilidades de uma nova política industrial no Brasil. Pesquisa \& Debate, São Paulo, v. 19, n. 2 (34), p. 255-271, 2008.

BERCOVICl, Gilberto. Direito econômico do petróleo e dos recursos minerais. São Paulo: Quartier Latin, 2011.

Infraestrutura e desenvolvimento. In: BERCOVICI, Gilberto; VALIM, Rafael (Coord.). Elementos de direito da infraestrutura. São Paulo: Contracorrente, 2015. p. 17-26.

ataque ao pré-sal. Conversa Afiada, 5 fev. 2016. Disponível em: <www.conversaafiada. com.br/economia/pre-sal-nem-o-entreguismo-do-cerra-nem-a-esperteza-do-braga>. Acesso em: 5 fev. 2016.

. Petrobras: monopólio estatal e política concorrencial. Revista Fórum de Direito Financeiro e Econômico, Belo Horizonte, ano 3, n. 5, p. 135-148, mar.-ago. 2014.

Cem anos da Constituição de Weimar. In: BERCOVICl, Gilberto (Coord.). O debate de Weimar e as origens do direito econômico, São Paulo: Quartier Latin, 2019. p. 457-470.

BIELSCHOWSKY, Ricardo. Pensamento econômico brasileiro: o ciclo ideológico do desenvolvimento. Rio de Janeiro: Contraponto, 1988.

BRASIL. Constituição da República Federativa do Brasil de 1988. 50. ed. Brasília: Edições Câmara, 2016.

BRASIL. Senado Federal. Projeto de lei $n^{\circ} 131$, de 2015. Brasília: Senado Federal, 19 mar. 2015. Disponível em: <www25.senado.leg.br/web/atividade/materias/-/materia/120179>. Acesso em: 3 dez. 2020.

CAMAROTTO, Murillo; JUBÉ, Andrea. Conteúdo nacional é danoso, conclui TCU. Valor Econômico, Brasília, 27 jun. 2016. Disponível em: <https://valor.globo.com/brasil/noticia/2016/06/27/conteudo-nacional-e-danoso-conclui-tcu.ghtml>. Acesso em: 4 dez. 2020.

CLĖVE, Clèmerson Merlin; MARTINS, Alessandra Ferreira. Princípios constitucionais da atividade econômica petrolífera e lei $n^{\circ} 9.478$ de 1997. Revista de Direito Administrativo \& Constitucional, Belo Horizonte, ano 4, n. 18, p. 43-45, out.-dez. 2004.

COMPARATO, Fábio Konder. O indispensável direito econômico. Revista dos Tribunais, São Paulo, n. 353, p. 22, mar. 1965.

D'ALMEIDA, Albino Lopes. Indústria do petróleo no Brasil e no mundo: formação, desenvolvimento e ambiência atual. São Paulo: Blucher, 2015.

FURTADO, Celso. Formação econômica do Brasil. São Paulo: Companhia das Letras, 2007.

GRAU, Eros Roberto. A ordem econômica na Constituição de 1988. 5. ed. São Paulo: Malheiros, 2000.

HESSE, Konrad. A força normativa da Constituição. Tradução Gilmar Ferreira Mendes. Porto Alegre: Sergio Antonio Fabris Editor, 1991.

LEITE, Antonio Dias. A energia do Brasil. 2. ed. Rio de Janeiro: Elsevier, 2007.

LIMA, Haroldo. Petróleo no Brasil: a situação, o modelo e a política atual. São Paulo: Synergia, 2008.

LIMA, Paulo César Ribeiro (Coord.). Os desafios do pré-sal. Brasília: Edições Câmara, 2009. (Série

Cadernos de Altos Estudos, n. 5.) 
MANGABEIRA, Francisco. Imperialismo, petróleo, Petrobras. Rio de Janeiro: Zahar, 1964.

MASCARO, Alysson Leandro. Estado e forma política. São Paulo: Boitempo, 2013.

MASSONETTO, Luís Fernando. Aspectos macrojurídicos do financiamento da infraestrutura. In: BERCOVICl, Gilberto; Valim, Rafael (Coord.). Elementos de direito da infraestrutura. São Paulo: Contracorrente, 2015. p. 27-52.

MAZZUCATO, Mariana. O Estado empreendedor: desmascarando o mito do setor público vs. setor privado. Tradução Elvira Serapicos. São Paulo: Portfolio-Penguin, 2014.

MORAES, Alexandre de. Regime jurídico da concessão para exploração de petróleo e gás natural. Revista de Direito Constitucional e Internacional, São Paulo, ano 9, jul.-set. 2001.

MORAIS, José Mauro de. Petróleo em águas profundas: uma história tecnológica da Petrobras na exploração e produção offshore. Brasília: Ipea; Petrobras, 2013.

NASSIF, Lourdes. TCU na contramão do desenvolvimento nacional. GGN, São Paulo, 12 jul. 2016. Disponível em: <http://jornalggn.com.br/noticia/tcu-na-contramao-do-desenvolvimento-nacional>. Acesso em: 4 dez. 2020.

NÉBIAS, Diogo; WARDE JÚNIOR, Walfrido Jorge. Breves notas sobre o project finance como técnica de financiamento da infraestrutura. In: BERCOVICI, Gilberto; VALIM, Rafael (Coord.). Elementos de direito da infraestrutura. São Paulo: Contracorrente, 2015.

OCTAVIANI, Alessandro. Estudos, pareceres e votos de direito econômico. São Paulo: Singular, 2014.

Recursos genéticos e desenvolvimento: os desafios furtadiano e gramsciano. São Paulo: Saraiva, 2013.

PETROBRAS. Prêmios e certificações. [s.d.]. Disponível em: <http://www.petrobras.com.br/pt/quem-somos/trajetoria/premios-e-certificacoes>. Acesso em: 3 dez. 2020.

PINHO, Cláudio A. Pré-sal: história, doutrina e comentários às leis. Belo Horizonte: Legal, 2010.

PRADO JR., Caio. História econômica do Brasil. São Paulo: Brasiliense, 1987.

RANGEL, Ignácio. Dualidade básica da economia brasileira (1957). In: Obras reunidas. Rio de Janeiro: Contraponto, 2012. v. 1. 3.ed. p. 285-354.

RECEBEMOS o prêmio Offshore Technology Conference 2015. Fatos e dados, 3 fev. 2015. Disponível em: <www.petrobras.com.br/fatos-e-dados/recebemos-o-premio-offshore-technology-conference-2015.htm>. Acesso em: 3 jun. 2019.

ROCHA, Igor; MAGACHO, Guilherme. Ainda há espaço para o conteúdo local?. Valor, São Paulo, p. A10, 15 dez. 2016.

ROOS, Breno Carvalho. Economia do petróleo e desenvolvimento: estudo exploratório sobre as perspectivas do pré-sal brasileiro. 2013. Dissertação (Mestrado em Economia) - Centro de Ciências Sociais Aplicadas, Universidade Federal do Rio Grande do Norte, Natal, 2013.

SADER, Emir; GENTILI, Pablo (Org.). Pós-neoliberalismo: as políticas sociais e o Estado democrático. Rio de Janeiro: Paz e Terra, 1995.

SCHUMPETER, Joseph Alois. Teoria do desenvolvimento econômico: uma investigação sobre lucros, capital, crédito, juro e ciclo econômico. Tradução Maria Sílvia Passos. São Paulo: Nova Cultural, 1985.

TIBIRIÇÁ, Maria Augusta. O petróleo é nosso: a luta contra o "entreguismo", pelo monopólio estatal. Petrópolis: Vozes, 1983.

WARDE JÚNIOR, Walfrido Jorge; BERCOVICl, Gilberto; SIQUEIRA NETO, José Francisco. Um plano de ação para o salvamento do projeto nacional de infraestrutura. São Paulo: Contracorrente, 2015. 